\title{
Política cultural y crisis económica: algunas reflexiones a propósito de la reforma de la Ley del Cine
}

\section{Cultural Policy and the Financial Crisis: Some Reflections on the Cinema Act}

\author{
María-Jesús Díaz-González \\ Profesora Contratada Interina \\ (Universidade da Coruña)
}

Este artículo se ha elaborado en el marco del proyecto de I+D

Las políticas de comunicación en la Europa Mediterránea

en el contexto de la crisis financiera (2008-2015).

Análisis del caso español (referencia CSO2013-42523-P),

financiado por el Ministerio de Economía y

Competitividad del Gobierno de España.

Fecha de recepción: 15 de abril de 2016

Fecha de revisión: 2 de julio de 2016

Para citar este artículo: Díaz-González, M. J. (2016): Política cultural y

crisis económica: algunas reflexiones a propósito de la reforma de la Ley del

Cine, Icono 14, volumen 14 (2), pp. 182-203. doi: 10.7195/ri14.v14i2.975 


\section{Resumen}

En España, desde el año 2008, las decisiones políticas que están afectando a la industria cinematográfica se han justificado con frecuencia por la situación general de crisis económica. Una de estas decisiones ha sido la reforma de la Ley del Cine, que entró en vigor a comienzos de 2016. El objetivo de este trabajo es reflexionar sobre aquellos aspectos de la reforma que pueden tener mayor repercusión en el fomento de la cinematografia; y aportar argumentos para valorar si estas reformas se han debido a la crisis económica o a las decisiones de política cultural. Los resultados indican que las reformas con mayor repercusión podrían ser: las características de las nuevas ayudas para la producción de largometrajes; las obligaciones de gasto en el territorio nacional; la intensidad máxima permitida para las ayudas; la obligación de reembolso de las ayudas en algunos casos; y la regulación de las producciones que pueden ser consideradas obras dificiles.

Palabras clave: Política pública - Cine - Crisis económica - Industria cinematográfica Industria cultural - Regulación audiovisual - Legislación audiovisual - Política y planificación de la cultura

\section{Abstract}

Since 2008, the financial crisis has often been cited as justification for certain political decisions affecting the film industry in Spain. One of these decisions was the reform of the Cinema Act, which came into effect in early 2016. The aim of this work is, firstly, to reflect on those aspects of the reform that are likely to have the greatest impact on the promotion of filmmaking, and secondly, to provide some arguments to assess whether these reforms can be put down to the financial crisis or to cultural policy decisions. The results show that the reforms likely to have the greatest impact are the characteristics of new subsidies for feature film production, the obligations to spend on national territory, the maximum permitted subsidy intensity, the obligations to reimburse subsidies in some cases, and the regulation of productions that could be considered difficult works.

Key Words: Public policy - Cinema, - Financial crisis - Film industry - Cultural industry 


\section{Introducción}

El cine es uno de los elementos fundamentales de las políticas culturales de la Unión Europea. "La participación de las instituciones europeas en la cultura encuentra en este sector su mayor impronta y, durante largo tiempo, fue uno de sus escasos ámbitos de actuación cultural" (Sierra, 2010: 46). El cine es cultura y por eso se justifica que reciba ayudas públicas (Beltrán, 2014); pero, indudablemente, es también industria y negocio. De esta dualidad deriva uno de los puntos habituales en el debate público sobre este sector.

En España, hay que destacar "la relevancia de la cinematografía en el marco de la política pública general en materia de cultura, toda vez que desde los orígenes del Estado democrático [...] el cine ha sido objeto de una atención particularizada y de una gestión autónoma"(Sierra, 2010: 151). Las competencias sobre la cinematografía en su vertiente cultural son concurrentes entre el Estado y las Comunidades Autónomas; en lo que se refiere a la regulación estatal, la ley del cine actualmente vigente se promulgó en 2007 (Ley 55/2007). Sierra considera que esta norma sigue un modelo de "aproximación a la actividad cinematográfica desde un prisma pretendidamente cultural y, para ello, propone un extenso abanico de ayudas públicas" (2010: 64). Como ejemplo se puede señalar que, esta ley se propuso dotar con recursos estables el Fondo de protección a la cinematografía y al audiovisual con el objetivo de proporcionar seguridad financiera a la industria del cine, especialmente a los sectores independientes, y reguló que

En los Presupuestos Generales del Estado se dotará anualmente un Fondo de Protección a la Cinematografía y al Audiovisual, cuya gestión se realizará por el Instituto de la Cinematografía y de las Artes Audiovisuales (ICAA), para atender, sin perjuicio de la existencia de otras dotaciones específicas, las ayudas previstas en esta Ley (Ley 55/2007, artículo 19, 3).

Esta ley fue bien elaborada (López González, 2008) y contó con el consenso del sector (B. Pena, entrevista personal, 23 febrero, 2016). Casado puntualiza que la mayor oposición a este ley vino de las televisiones privadas "que se mostraban (y se muestran) contrarias a la obligación de invertir en cine comunitario" (2013: 95). 
Desde su entrada en vigor hasta la actualidad, la norma ha sido modificada en cuatro ocasiones; la última modificación, de mayo de 2015, es de la que se ocupa este trabajo.

Una de las causas que han motivado esta última reforma ha sido la necesidad de actualizar la normativa española y adaptarla a la normativa europea sobre la materia. $\mathrm{Y}$, en este punto, hay que hacer referencia a la conocida como «Comunicación Cine». Se trata de la Comunicación de la Comisión Europa sobre la ayuda estatal a las obras cinematográficas y otras producciones del sector audiovisual que entró en vigor en noviembre de 2013. Esta Comunicación es el instrumento normativo que los Estados miembros tienen que cumplir cuando regulan mecanismos para apoyar a la industria cinematográfica, porque las ayudas que derivan de estos pueden afectar a las reglas de la competencia o distorsionar las reglas del mercado interior europeo (Real Decretoley 6/2015, exposición de motivos). La «Comunicación Cine» preveía un plazo de dos años -hasta noviembre de 2015- para que los Estados ajustasen a ella sus regímenes sobre financiación de películas, por tanto, España debía realizar este ajuste.

La otra causa que ha expuesto repetidamente la Administración Central para aprobar la última reforma de la Ley de Cine ha sido la situación de crisis económica. La publicación del Real Decreto-ley 6/2015 (RDL 6/2015) pone en marcha este proceso, y en él se alude a este problema con expresiones muy drásticas. Señala que la necesidad de modificar la Ley del Cine es extraordinaria y urgente, y considera que el sector cinematográfico está en riesgo cierto de colapso a corto plazo

El legislador debe buscar un necesario y permanente equilibrio que adapte las reglas que encauzan y fomentan la actividad cinematográfica a los cambios sustanciales del entorno económico y a la propia actualización de las reglas generales que lo configuran. Son algunos de esos cambios y el relato empírico de la crisis económica lo que, transcurridos siete años desde su entrada en vigor, justifican la modificación de la ley (RDL 6/2015, exposición de motivos).

Este es un trabajo sobre una reforma que acaba de implantarse $\mathrm{y}$, mientras se estaba preparando, no se ha podido contar con referencias de publicaciones científicas que hayan abordado ya la misma cuestión. 
Los trabajos más recientes sobre políticas públicas relativas al cine en España proceden tanto del ámbito del derecho como del ámbito de la comunicación; su perspectiva y metodología es diferente, y el conocimiento y comparación de ambas resulta muy enriquecedor. Sierra $(2009,2010,2011 a, 2011 b, 2012)$ es, sin duda, una de las mayores especialistas en esta materia. Las aportaciones de Álvarez Monzoncillo -una parte de ellas en coautoría con López Villanueva y otros- han sido continuadas a lo largo de los años, lo que aumenta su valor para la investigación (2002, 2003, 2006, 2007, 2015a, 2015b). Esta misma continuidad tienen los trabajos de García Santamaría, en este caso centrados en el sector de la exhibición cinematográfica (2009a, 2009b, 2013, 2015a, 2015b; Varela, 2009). Por último, uno de los últimos textos publicados dedicado específicamente a la intervención pública en el cine es el de Casado (2013); además, la investigación de este autor ha prestado especial atención a las políticas autonómicas sobre esta materia (2005).

\section{Método}

El objetivo de este trabajo es reflexionar sobre aquellos aspectos de la reforma que pueden tener mayor repercusión en el fomento de la cinematografía y, como consecuencia, en la industria cinematográfica; y aportar argumentos para valorar si estas reformas se han debido a la crisis económica o a las decisiones de política cultural. Con estos dos objetivos principales se diseñó la investigación teniendo en cuenta que la reforma de la Ley del Cine acaba de entrar en vigor, por tanto, no es el momento de realizar una investigación que la valore en sí misma, porque para ello será necesaria una perspectiva de su funcionamiento en los próximos años.

En consecuencia, el planteamiento de esta investigación se centra en determinar qué puntos de la reforma necesitarán un seguimiento para poder evaluar más adelante la incidencia de las políticas públicas en la industria cinematográfica española.

Para conseguir ambos objetivos se consideró que la metodología cualitativa era la más adecuada dadas las características de la investigación. La metodología cualitativa combinó el análisis documental y las entrevistas en profundidad con productores cinematográficos. Por una parte, el análisis documental se ha aplicado 
a la legislación europea y española relacionada con el objeto de estudio y a los trabajos científicos que aportan el contexto necesario de conocimiento e interpretación. Para ello se llevó a cabo una exhaustiva revisión bibliográfica en el ámbito nacional e internacional.

Por otra parte, se realizaron entrevistas en profundidad con agentes del sector. Las entrevistas en profundidad a los productores cinematográficos fueron semiestructuradas. Se elaboró un documento con ocho ítems sobre los que versaría la entrevista y se envió previamente a los entrevistados para que conocieran el enfoque y los objetivos del trabajo y así la entrevista resultara más efectiva. Estos ítems previos sirvieron de marco durante la conversación, pero se buscó que las respuestas fueran abiertas y que los entrevistados pudieran profundizar en áreas 0 temáticas no previstas (Miguel, 2005: 253). Las entrevistas se registraron mediante grabación y notas tomadas durante las mismas.

Los productores cinematográficos entrevistados fueron Borja Pena, de Vaca Films $^{1}$, y Chelo Loureiro, de Abano Producions ${ }^{2}$. Para la selección de los entrevistados se tuvieron en cuenta los criterios de representatividad en el colectivo de los productores cinematográficos españoles, experiencia, disposición a colaborar con la investigación, capacidad de comunicación, así como, que entendieran el propósito del trabajo (Ruiz Olabuénaga, 2012). Sin embargo, cabe destacar las limitaciones obvias derivadas de la selección de una muestra reducida pero considerada suficiente para esta primera investigación sobre la reforma de la ley del Cine. En futuras investigaciones sobre los posibles efectos de dicha ley se ampliará dicha muestra con el fin de ofrecer una visión más completa y realmente representativa del conjunto de los productores españoles.

\section{Desarrollo}

La reforma de la Ley del Cine entró en vigor el 1 de enero de 2016; excepto la Orden Ministerial por la que se regula el reconocimiento del coste de una película y la inversión del productor (Orden ECD/2784/2015, de 18 de diciembre), que lo hizo el 1 de marzo del mismo año. 
La reforma se articuló primero a través de un Real Decreto-ley, el 6/2015, de 14 de mayo; y se desarrolló, después, mediante un Real Decreto: el 1084/2015, de 4 de diciembre; y dos Órdenes Ministeriales: la Orden ECD/2796/2015, de 18 de diciembre, por las que se establecen las bases reguladoras de las ayudas previstas en el Capítulo III de la Ley 55/2007, de 28 de diciembre, del Cine, y se determina la estructura del Registro Administrativo de Empresas Cinematográficas y Audiovisuales; y la Orden ECD/2784/2015 a la que ya se ha hecho referencia.

Para lograr los objetivos de este trabajo, lo primero que se debe hacer es individualizar los aspectos más relevantes de la reforma de la Ley del Cine. El análisis documental y las entrevistas en profundidad permiten señalar los siguientes: el cambio de las ayudas para la amortización de largometrajes por las ayudas generales para la producción de largometrajes sobre proyecto; el modo de concretar la normativa europea sobre las obligaciones de gasto en el propio territorio nacional y sobre la intensidad máxima de las ayudas; la posibilidad de que en algunos casos las ayudas recibidas sean reembolsables y la regulación de las producciones que pueden ser consideradas obras difíciles.

La exposición que sigue se detiene en cada uno de estos puntos. Se empieza recogiendo el contenido de los artículos modificados $\mathrm{y}$, después, se introducen las reflexiones y argumentos sobre la repercusión de estos cambios y su motivación.

\subsection{Ayudas generales para la producción de largometrajes sobre proyecto en lugar de ayudas para la amortización de largometrajes (Ley 55/2007, artículo 26)}

Las ayudas para la amortización se concedían de forma automática para amortizar el coste de producción de las películas; la ayuda era a posteriori y estaba asegurada si el largometraje alcanzaba un número establecido de venta de entradas en las salas de exhibición. Por tanto, una empresa productora podía arriesgarse a hacer todas las películas que lograse financiar porque podía contar con esta ayuda estatal.

Además, estas ayudas a la amortización eran compatibles con las denominadas ayudas para la producción de largometrajes sobre proyecto.

DOI: ri14.v14i2.975 | ISSN: 1697-8293 | Año 2016 Volumen 14 Nº 2 | ICONO14 


\section{MONOGRÁFICO}

Con la reforma de la Ley, las ayudas se convierten en ayudas anticipadas para financiar el coste de producción de los proyectos, y los fondos totales para estas ayudas quedan establecidos de antemano en los Presupuestos Generales del Estado. Los proyectos de largometrajes que aspiren a estas ayudas serán puntuados de acuerdo con un baremo que ya se ha publicado (Orden ECD/2796/2015) y los fondos públicos solo se verán comprometidos en la medida en que haya presupuesto.

Como estas ayudas financian el coste de producción de las películas, la normativa que regula el reconocimiento del coste (0rden ECD/2784/2015) es fundamental para que el productor pueda tener seguridad para acceder a la ayuda. Esta normativa también ha sido reformada ahora.

Hay que añadir que con la reforma estas ayudas generales son incompatibles con las otras que se prevén para la producción de largometrajes: las llamadas ahora ayudas selectivas ${ }^{3}$.

Es previsible que este cambio en las ayudas a la producción tenga repercusiones importantes en el sector cinematográfico, sobre todo, porque con los fondos de las nuevas ayudas -escasos y no ampliables- se van a poder financiar pocas películas, muchas menos que con el sistema de ayudas a la amortización. En consecuencia, es probable que muchas producciones estén peor financiadas $\mathrm{y}$, como es lógico, la calidad del cine empeore.

El sistema anterior daba mayor libertad al productor porque permitía poner en marcha los proyectos de los que esperaba unos ingresos suficientes de taquilla. Ahora ya no será así, como señala Borja Pena (Vaca Films):

En estos cuatro años (2011-2015), los responsables políticos ${ }^{4}$ se empeñaron en que había que cambiar la Ley porque querían que las ayudas fueran a priori, para poder controlarlas y evitar que en épocas de crisis económica los Presupuestos Generales del Estado estuvieran comprometidos. Con las ayudas a la amortización, que se convocaban para películas producidas dos o tres años antes, si la Administración no pagaba esas ayudas con las que los productores habían contado en el momento de hacer la película, entonces, llevaba a la quiebra 
a las empresas o a los bancos que adelantaron los préstamos. Con la reforma, el Gobierno ha conseguido lo que buscaba: tener un control a priori, férreo, con un presupuesto dotado escasamente.

Es cierto que, el sistema de ayudas a la amortización tenía muchos problemas. Por ejemplo, producir una película y recibir la ayuda tres o cuatro años después, con lo que eso supone al productor de gastos financieros y mucho riesgo en el banco, que, además, no está dispuesto a financiar otra película al mismo productor hasta que este no cobra. También, la obligación de llegar a la taquilla establecida porque si no, no se recibía nada de la ayuda; cien entradas vendidas arriba o abajo, suponía recibir toda la ayuda o no recibir nada. Pero, estos problemas se podrían haber resuelto con pequeños ajustes en la Ley: eliminando la rigidez en la obligación sobre la taquilla, acortando los plazos para recibir las ayudas: a seis meses, por ejemplo. Sin embargo, esto no se hizo porque desde la Administración Central se quería tener un control exacto y a priori del gasto (B. Pena, entrevista personal, 23 febrero, 2016).

Como se ha explicado antes, los proyectos que concurran a las ayudas generales y a las ayudas selectivas para la producción serán valorados de acuerdo a un baremo que se hizo público con la reforma de la Ley del Cine. Los productores consideran que en el baremo se ha incluido un criterio que hará al cine aún más dependiente de la inversión de los grupos televisivos (Moreno, 2005; Sierra, 2011b), y consideran que esto podría tener consecuencias muy negativas en la industria. El baremo que ahora se introduce para conceder las ayudas generales tiene un apartado en el que se valora la viabilidad económica y financiera del proyecto y difusión, y otorga entre 9 y 15 puntos a los proyectos que presenten contrato o compromiso firme previo rodaje con un medio de comunicación audiovisual; de hecho, es lo que más se valora en este apartado. El baremo para las ayudas selectivas adjudica entre $1 \mathrm{y}$ 4 puntos si se cuenta con ese contrato o compromiso firme. Sin embargo, este no es un requisito de fácil cumplimiento, tal como menciona Chelo Loureiro (Abano Producions):

Cumplir esta condición resultará muy complicado para la mayor parte de los proyectos. Tener un compromiso firme con RTVE es difícil porque los modos 


\section{MONOGRÁFICO}

de trabajo de la corporación pública hacen que tarden muchísimo en decidir qué proyectos van a apoyar. Y los grupos privados con más capacidad de financiación: Mediaset España y Atresmedia, quieren un tipo de cine y están en su derecho (C. Loureiro, entrevista personal, 24 febrero, 2016).

Más arriba se hizo referencia a la importancia que tendrá la normativa sobre el reconocimiento del coste de una película para recibir las ayudas. $\mathrm{Y}$, sobre este punto, los productores señalan un serio problema: la inseguridad jurídica que se deriva de la dificultad de interpretar la norma:

El sector pidió durante años a la Administración Central una normativa más clara respecto al reconocimiento de costes, porque cuando empezó la crisis económica, la Administración empezó a aplicar criterios e interpretaciones que no eran los que tenían antes. Parece que hubiera habido una orden para interpretar la norma de un modo muy perjudicial para el sector, empezaron a dejar de reconocer costes de producción por cantidades muy importantes, las inspecciones eran continuas y había muchas dificultades para llegar a obtener completas las ayudas que correspondían a la película. Como consecuencia, hay muchos procesos judiciales abiertos por parte de las productoras para lograr el reconocimiento de costes (B. Pena, entrevista personal, 23 febrero, 2016).

Y, en la misma línea se puede añadir que

Casi de modo sistemático no están reconociendo los costes de las películas, y la ayuda queda tan reducida que es un quebranto para las empresas. Si esto, por ejemplo, genera una deuda con tu banco de $150.000 €$, sabes que no te concederán otro crédito y que no podrás empezar un nuevo proyecto. Te ves obligado a demandar; la Administración sabe que perderá esas demandas pero sigue obstaculizando el reconocimiento de costes (C. Loureiro, entrevista personal, 24 febrero, 2016).

La nueva normativa sobre el reconocimiento del coste de una película no previó un periodo de transitoriedad entre el anterior sistema de reconocimiento y el actual, vigente desde el 1 de marzo de 2016. Esta es una cuestión con importantes 
repercusiones para las productoras y una manifestación más de la inseguridad jurídica con la que trabajan. En la práctica, todas las películas que no lograron presentar sus costes antes del 1 de marzo de 2016 están sometidas al nuevo sistema. Pero hay que tener en cuenta que muchas películas plantearon sus costes de desarrollo, preproducción, rodaje de acuerdo con la anterior normativa y siguiendo los criterios anteriores; $\mathrm{y}$, si la película no estuvo terminada o estrenada antes del 1 de marzo de 2016, el productor tendrá que aplicar unos criterios para el reconocimiento del coste que desconocía en el momento de plantear el proyecto (B. Pena, entrevista personal, 23 febrero, 2016). Si la Administración hubiera previsto un periodo transitorio entre una norma y otra, el sector se hubiera visto menos perjudicado.

\subsection{Intensidad máxima de las ayudas (Ley 55/2007, artículo 20)}

La «Comunicación Cine» establece que las subvenciones, incentivos fiscales y otro tipo de apoyo financiero a las obras cinematográficas son ayudas de Estado. La existencia de estas ayudas podría afectar al comercio entre Estados miembros de la Unión Europea, porque los productores y obras audiovisuales que reciben ayudas probablemente contarán con una ventaja financiera, y por ende competitiva, sobre los que no la reciben. Por ello, la Comisión Europea está obligada a evaluar la compatibilidad de las ayudas al sector audiovisual con el mercado interior, al igual que hace con las ayudas estatales a otros sectores (Comunicación de la Comisión, 2013, artículo 8). Como consecuencia, la «Comunicación Cine» orienta sobre una intensidad máxima, un tope, para las ayudas (artículo 52, apartados 2, 3 y 4).

La reforma de la Ley del Cine aplica este principio, y establece que en las ayudas generales y selectivas para la producción de largometrajes sobre proyecto, la suma de las ayudas directas y los incentivos fiscales no podrá superar el 50\% del coste del largometraje (Orden ECD 2796/2015, artículo 11, 2). Hay algunas excepciones a este límite: las producciones transfronterizas y las obras audiovisuales difíciles.

Las producciones transfronterizas son las que están financiadas por más de un Estado de la UE y en ellas participan productores de más de un Estado; en este caso, las ayudas pueden llegar hasta el $60 \%$ del coste de la película. Las obras 
audiovisuales difíciles -a ellas se hace referencia más adelante en este trabajopueden recibir ayudas que alcanzan entre el 60 y el 75\% de su coste.

Es conveniente señalar, de nuevo, la importancia de la normativa que regula el reconocimiento del coste de una película porque, como se ve, el conjunto de ayudas recibidas depende del coste reconocido ${ }^{5}$.

Además, la cuantía de las ayudas tiene otra limitación aparte de su intensidad máxima. Las ayudas directas generales serán de 1.400.000 € como máximo y esta cantidad no puede superar el $40 \%$ del coste del largometraje (0rden ECD 2796/2015, artículo 17). Las ayudas directas selectivas serán de $500.000 €$ como máximo y esta cantidad tampoco puede superar el 40\% del coste (artículo 23).

En esta cuestión de la intensidad máxima de las ayudas, los límites aprobados en la reforma de la Ley del Cine son más restrictivos que los permitidos por la «Comunicación Cine». Por ejemplo, esta Comunicación indica que los límites no se aplican a las obras audiovisuales difíciles (Comunicación de la Comisión, 2013, artículo 52, 2); sin embargo, como se acaba de señalar, en nuestro país se aplicará un límite entre el $60 \mathrm{y}$ el 75\%.

Además de esto, los productores manifiestan que hay un desarrollo normativo insuficiente respecto al modo de aplicar las deducciones fiscales a la inversión en producción de películas, lo que conduce de nuevo al problema de la inseguridad jurídica. Los productores entrevistados señalan que actualmente, la deducción fiscal para la inversión en producción audiovisual es de un 19\% de media (20\% de deducción en el primer millón de euros invertido y $18 \%$ en los siguientes). Sin embargo, hay que precisar que no toda esa deducción fiscal llega a los costes de la película, sino que las sociedades que invierten la aplican en su impuesto de sociedades. Como consecuencia, cuando se conceda una ayuda del ICAA, para los productores va a ser difícil saber de qué cantidad podrán disponer para no superar la intensidad máxima total y necesitarán ser muy prudentes con la financiación de sus proyectos. 


\subsection{Obligación de gasto en el territorio nacional (Ley 55/2007, artículo 20)}

Para poder optar a las ayudas generales y selectivas a la producción, al menos el 50\% del presupuesto del largometraje se debe gastar en España o debe revertir en autores, equipos técnicos, artísticos o de servicios españoles (RD 1084/2015, artículo 24, 3). Si se trata de una coproducción con empresas extranjeras, este requisito se aplica solo a los gastos que corresponden al porcentaje de participación española en la película

En las ayudas generales, esta obligación se precisa y se establece un límite máximo de 2.000.000 € para el gasto en España (Orden ECD 2796/2015, artículo 14, 1c).

Estos requisitos de territorialización de los gastos de producción cinematográfica que recoge la reforma de la Ley del Cine son una decisión de nuestros responsables políticos y no vienen impuestos por la «Comunicación Cine». De acuerdo con esta,

Los requisitos de territorialización del gasto constituyen una restricción del mercado interior de producción audiovisual. Por consiguiente, la Comisión encargó un estudio externo sobre las condiciones de territorialización impuestas a las producciones audiovisuales que se finalizó en 2008. [...] el estudio no llegaba globalmente a unas conclusiones claras: no logró dilucidar si los efectos positivos de las condiciones de territorialización superaban a los efectos negativos (Comunicación de la Comisión, 2013, artículo 28).

En consecuencia, la Comisión Europa puede aceptar que un Estado miembro aplique estos requisitos, aunque, "en cualquier caso, de conformidad con el derecho de la UE, los Estados miembros no están obligados a imponer requisitos de territorialización de los gastos" (Comunicación de la Comisión, 2013, artículo 38). $\mathrm{Si}$, de todos modos, deciden imponerlos, hay un límite del 50\% del presupuesto de producción global (artículo 50).

Como se puede deducir, la Administración Central ha decidido aplicar una obligación muy alta de gasto en el propio territorio. Esto podría dificultar la 
competitividad y calidad de las producciones o coproducciones españolas, puesto que en otros países europeos vecinos no existe esta restricción, y los posibles inversores buscan las mejores condiciones para su negocio.

\subsection{Las ayudas a la producción de largometrajes serán reembolsables en algunos casos (Ley 55/2007, artículo 20)}

Este reembolso o devolución de la ayuda habrá que hacerlo si los ingresos que genere la explotación de la película en salas de exhibición en España son tres veces superiores al coste de producción del largometraje que haya reconocido el ICAA, y siempre que, como consecuencia, haya un beneficio real para el productor (0rden ECD 2796/2015, artículo 13).

Si se constata que hay un beneficio real, el reembolso de la ayuda puede ser total o parcial. Si el beneficio real supera el 300\% del importe de la ayuda, el reembolso será total. Si el beneficio supera el $200 \%$, el reembolso será del 50\%; y, si supera el $150 \%$, será del $25 \%$.

El reembolso de las ayudas podría despertar, de entrada, cierta alarma en la industria cinematográfica, pero cabe pensar que su incidencia real será muy pequeña, porque el beneficio real de la media de las películas españolas no alcanza esos porcentajes. Además, como ha explicado Borja Pena (Vaca Films):

En sí misma, la devolución de la ayuda no es perjudicial, responde a un principio de solidaridad. Lo que ocurre es que en los casos en los que el reembolso llegue a darse, sería preferible que la Ley hubiera previsto que se destinara de nuevo a la producción de cine. Este es el sistema que se sigue en Francia: cuando una película alcanza un determinado nivel de beneficio, el productor tiene que ingresar una parte en una cuenta que tiene abierta en el Centre national du cinemá et de l'image animée (CNC) para reinvertirlo obligatoriamente en sus siguientes películas. Con este sistema, el reembolso es un incentivo (B. Pena, entrevista personal, 23 febrero, 2016). 


\subsection{Producciones audiovisuales que serán consideradas obras difíciles (RD 1084/2015, artículo 21, 2)}

La «Comunicación Cine» alude a las obras audiovisuales, e indica que "en virtud del principio de subsidiariedad incumbe a cada Estado miembro establecer una definición de "película difícil» según los parámetros nacionales" (Comunicación de la Comisión, 2013, artículo 52, 2). España ha aprovechado la reforma de la Ley del Cine para concretar esta definición. Así, lo que queda establecido como obra difícil son los cortometrajes, las producciones dirigidas por un nuevo realizador cuyo presupuesto de producción no supere los $300.000 €$ y las obras audiovisuales rodadas en alguna de las lenguas cooficiales distintas al castellano que se proyecten en España en dicho idioma cooficial o subtitulado.

Como se explicó anteriormente, estas obras difíciles pueden recibir una intensidad de ayudas mayor para su producción.

Sobre este punto, la FAPAE manifestó expresamente la postura de los productores audiovisuales. Respecto al presupuesto para obras de nuevos realizadores -un máximo de 300.000 euros-, señala: "Si el objetivo final es promover la incorporación de nuevos realizadores al sector, debe dárseles también la oportunidad de participar en contenidos de primer nivel, máxime cuando ya la propia definición de nuevo realizador (dos producciones) limita el disfrute de estas condiciones diferenciadas" (FAPAE, 2015).Y respecto a las obras en lenguas cooficiales distintas al castellano,

la Administración Central debería haber dejado esta consideración a las Administraciones Autonómicas con lenguas cooficiales distintas del castellano, en la seguridad de que ellas podrían valorar en cada caso con mucho mejor criterio la complejidad de la utilización de las mismas, como idioma vehicular de una producción audiovisual y graduar, en consecuencia, la intensidad de la ayuda que debería admitirse (FAPAE, 2015).

Antes de terminar este epígrafe, conviene detenerse en la regulación de la denominada «excepción cultural». La inclusión de este punto en la reforma de la Ley 
del Cine también incide en las medidas de fomento de la cinematografía y es algo en lo que la Comisión Europea viene insistiendo desde hace tiempo (Sierra, 2012), pero no es una medida de política cultural que se justifique por el contexto de crisis económica.

La «Comunicación Cine» señala que las ayudas al sector audiovisual deben promover la cultura (lo que no excluye que las obras tengan carácter comercial) y que la definición de las actividades culturales es una responsabilidad de los Estados miembros, que deben tener un mecanismo de verificación pertinente y eficaz para comprobar el carácter cultural de las obras audiovisuales que reciben ayudas (Comunicación de la Comisión, 2013, artículo 25).

Como consecuencia de esta disposición, en el RD 1084/2015 se establece: “Solo podrán concederse ayudas a la producción de aquellas obras cinematográficas y audiovisuales que tengan acreditado su carácter cultural en atención a su contenido, su vinculación con la realidad cultural española o su contribución al enriquecimiento de la diversidad cultural de las obras cinematográficas que se exhiben en España" (artículo 22, 1). Los proyectos para la producción de largometrajes que quieran acceder a las ayudas generales o selectivas, y las inversiones en producción audiovisual (películas y series) que no soliciten ayudas pero quieran beneficiarse de los incentivos fiscales previstos deben obtener un certificado cultural según el procedimiento que se ha previsto en la 0rden ECD 2796/2015, artículo 12.

En el año 2010, ya se introdujo en la normativa española sobre cine el «test cultural» porque la Comisión Europea consideró que el sistema español de ayudas a la amortización de largometrajes podía ser contradictorio con la normativa europea, puesto que estas ayudas eran automáticas. Esta es una cuestión muy compleja desde el punto de vista conceptual y jurídico, pero el excelente trabajo de investigación de Beltrán Martínez posibilita conocer con profundidad el origen y el estado de esta cuestión hasta la reforma de la que se ocupa este estudio (Beltrán, 2014). 


\section{Conclusiones}

En esta investigación se ha querido reflexionar sobre aquellos aspectos de la reforma con mayor repercusión en el fomento de la cinematografía y de su industria junto con la motivación de estos cambios. Al tratarse de una reforma tan reciente ha sido preciso abordar la descripción de la ley y el análisis de sus posibles consecuencias apoyándose en el análisis comparativo de la legislación existente y las aportaciones de los agentes del sector.

Cabe señalar que resulta difícil exponer las posibles consecuencias de esta ley al abordar cambios recientes, cuya vigencia no llega al año, y cuyos efectos todavía no se han desarrollado en toda su extensión.

Sin embargo, una conclusión fundamental de la reforma de la Ley del Cine deriva del hecho de que todos los cambios que se aprueban con la intención de mejorar las ayudas al sector no son acompañados, una vez más, por un compromiso de la Administración para que el Fondo de protección a la cinematografía y al audiovisual tenga una dotación mínima. Sin esto, el cine no puede contar con un respaldo financiero estable y cualquier normativa, por buena que sea, no será del todo efectiva. Este vacío es más una cuestión de política cultural que de entorno económico de crisis: en 2007, se planteó que este Fondo tendría que tener una dotación de entre 60 y 100 millones de euros (López González, 2008: 196), y, estas cantidades representan una proporción mínima en unos Presupuestos Generales del Estado que ascienden a más de cuatrocientos mil millones de euros ${ }^{6}$.

Dicho esto, los resultados que se acaban de exponer permiten aportar varios argumentos para valorar si las reformas señaladas se deben más a la crisis o a la política.

Por una parte, las medidas adoptadas manifiestan una clara voluntad de control de las ayudas a la cinematografía por la vía de destinar pocos recursos, asignar a los proyectos cantidades fijas desde el principio desligadas de su trayectoria comercial -excepto para devolverlas si el beneficio real de la película es significativo- y condicionarlas al reconocimiento de costes que debe hacer la Administración. 


\section{MONOGRÁFICO}

Por otra parte, la cuestión del reconocimiento del coste de las películas pone de manifiesto la inseguridad jurídica que percibe el sector. Esta se refleja también en la indeterminación sobre el modo en que va a aplicarse el cálculo de la intensidad máxima de las ayudas. El cine, como otras industrias, precisa de un entorno seguro y estable para su desarrollo.

Por último, nuestros responsables políticos han optado por una aplicación restrictiva del marco establecido en la «Comunicación Cine». La regulación de la territorialización del gasto, de la intensidad máxima de la ayudas, del posible reembolso y de las ayudas para obras difíciles que se ha establecido en la reforma de la Ley del Cine tiende a incorporar los niveles más restrictivos que permite la Unión Europea.

El entorno económico en que se encuentra España desde hace casi diez años tiene necesariamente que influir en las decisiones sobre el gasto público en la cultura, sin embargo, de acuerdo con los argumentos expuestos, el planteamiento de política cultural de los responsables de la reforma parece haber sido más determinante que la crisis económica.

Conviene, también, señalar que lo planteado en este estudio se podría completar y reforzar con la investigación de los datos sobre la aportación que el sector del cine hace a la economía española. Estos datos podrían demostrar que es mucho más lo que el Estado ingresa por impuestos o cuotas de la Seguridad Social que lo que gasta en cinematografía. Además, es un sector que crea empleo, y empleo joven, cualificado y bien remunerado. A todo esto se puede añadir, como ponen de manifiesto algunas investigaciones recientes (García Fernández, 2015; Martínez Expósito, 2015; Binimelis, Cerdán \& Fernández-Labayen, 2015), que la aportación del cine es también eminente para la creación de marca país.

En próximos trabajos se retomará esta investigación con el fin de determinar las consecuencias reales y el impacto que está teniendo la reforma de esta ley en el sector. 


\section{Notas}

[1] http://www.vacafilms.com/quienes-somos/

[2] http://www.abano.es/es/chelo.html

[3] Las ayudas selectivas para la producción de largometrajes sobre proyecto se conceden a productores independientes para proyectos de especial valor cinematográfico, cultural o social, sean de carácter documental o experimental, o incorporen nuevos realizadores. Las ayudas generales se destinan a todas las empresas productoras.

[4] Por responsables políticos se entiende el Gobierno del Partido Popular, que ocupó el poder en este periodo.

[5] "A la hora de determinar si se respeta la intensidad máxima de ayuda habrá que tener en cuenta el importe total de las medidas de ayuda pública de los Estados miembros a la actividad o proyecto subvencionados, independientemente de si la subvención se financia con fondos locales, regionales, nacionales o de la Unión. Ahora bien, los fondos otorgados directamente por los programas de la UE como MEDIA sin la participación de los estados miembros en la decisión de subvención no son recursos estatales, por lo que las ayudas concedidas en virtud de los mismos no se tienen en cuenta a la hora de analizar si se respetan los límites de subvención" (Comunicación de la Comisión, 2013, artículo 54).

[6] En el siguiente enlace se puede consultar la información sobre los Presupuestos Generales del Estado del año en curso y de años anteriores: http://goo.gl/0JJDPN

\section{Referencias}

Álvarez-Monzoncillo, J. M., \& Zallo, R. (2002). Las políticas culturales y de comunicación para el desarrollo de los mercados digitales: un debate necesario. Zer(13), 77-94. Recuperado de http://goo.gl/IS8ia0 el 18 de marzo de 2016.

Álvarez-Monzoncillo, J. M. (2003). La industria cinematográfica: enfermedades crónicas e incertidumbres ante el mercado digital. En E. Bustamante Ramírez (Coord.), Hacia un nuevo sistema mundial de comunicación: industrias culturales en la era digital (pp. 107-140). Barcelona: Gedisa.

Álvarez-Monzoncillo, J. M., \& López-Villanueva, J. (2006). La situación de la industria cinematográfica española: políticas públicas ante los mercados digitales. Documento de trabajo 92/2006, Fundación Alternativas. Recuperado de http://goo.gl/MoAEhe el 22 de marzo de 2016.

DOI: ri14.v14i2.975 | ISSN: 1697-8293 | Año 2016 Volumen 14 NN$^{\circ} 2$ | ICONO14 


\section{MONOGRÁFICO}

Álvarez-Monzoncillo, J. M., \& López-Villanueva, J. (2007). Situación de la industria cinematográfica española: políticas públicas ante los mercados digitales. En J. M. Álvarez Monzoncillo, Alternativas de politica cultural: las industrias culturales en las redes digitales (disco, cine, libro, derechos de autor) (pp.107-164). Barcelona: Gedisa.

Álvarez-Monzoncillo, J.M. \& López-Villanueva, J. (2015a). Vidas paralelas de las películas: circuitos estratificados de distribución y consumo. adComunica. Revista de Estrategias, Tendencias e Innovación en Comunicación, 10, 21-40. doi: http://dx.doi.org/10.6035/2174-0992.2015.10.3

Álvarez-Monzoncillo, J.M., Baraybar, A. \& López-Villanueva, J. (2015b). Audiovisual production in Spain. Fewer resources, same problems, new challenges. Economia della Cultura, XXV(2), 211-222. doi:http://dx.doi.org/10.1446/81241

Beltrán, M. (2014). Consideraciones en torno a la introducción del «test cultural» en la normativa española de regulación del cine (Cuadernos de Derecho de la Cultura, Vol. 6). (I. I. UC3M-UNED, Ed.) Getafe, Madrid, España. Recuperado de http://goo.gl/q5fUaQ el 15 de febrero de 2016.

Binimelis, M., Cerdán, J., \& Fernández-Labayen, M. (2015). In and out: the transnational circulation of Spanish cinema in digital times. Journal of Spanish Cultural Studies,16(1), 1-8. doi:http://dx.doi.org/10.1080/14636204.2015.1042324

Casado, M. Á. (2005). Nuevas estrategias para el desarrollo del sector audiovisual en las comunidades autónomas. Ámbitos(13-14), 109-131.

Casado, M. Á. (2013). La intervención pública en el cine. En J. Clares, M. Á. Casado, D. Fernández-Quijada, \& J. Guimerá, Políticas culturales y de comunicación: la intervención pública en cine, televisión y prensa (pp. 59-114). Barcelona: UOC.

FAPAE. (4 de Diciembre de 2015). Comunicado de FAPAE sobre la aprobación hoy del Real Decreto que desarrolla el nuevo sistema de financiación del audiovisual. Recuperado de http://goo.gl/OVXyma el 15 de marzo de 2016.

García-Fernández, E. (2015). Marca e identidad del cine español. Proyección nacional e internacional entre 1980 y 2014. Madrid: Fragua.

García-Santamaría, J. V. (2009a). El futuro de la exhibición: la transformación de los complejos de cine en complejos de ocio. Telos(78), 150-158. Recuperado de https://goo.gl/v7bqTe el 22 de marzo de 2016.

García-Santamaría, J. V. (2009b). Operaciones de concentración en la exhibición española y análisis de la competencia. Área Abierta(22). Recuperado de https:// goo.gl/eQ5Dh5 el 22 de marzo de 2016. 
García-Santamaría, J. V. (2013). Digitalización de salas de cine y 3D en España: la oportunidad perdida de una potencia mundial en el sector de la exhibición. L'Atalante(16), 79-85.

García-Santamaría, J. V. (2015a). La exhibición cinematográfica en España. Madrid: Cátedra.

García-Santamaría, J. V., \& Maestro, L. (2015b). La exhibición cinematográfica española: una industria en recesión. adComunica. Revista de estrategias, tendencias e innovación en comunicación(10), 77-97. doi: http://dx.doi. org/10.6035/2174-0992.2015.10.6

López-González, J. (2008). Ley del Cine 2007. En C. Padrós, \& J. López-Sintas (Dir.), Estudios sobre Derecho y Economía del cine. Adaptado a la Ley 55/2007 del cine (pp. 177-207). Barcelona: Atelier Libros Jurídicos.

Martínez-Expósito, A. (2015). Cuestión de imagen: cine y Marca España. Vigo: Academia del Hispanismo.

Miguel, R.-d. (2005). La entrevista en profundidad a los emisores y los receptores de los medios. En R. Berganza, \& J. A. Ruiz-San-Román, Investigar en Comunicación. Guía práctica de métodos y técnicas de investigación social en Comunicación (pp. 251-263). Madrid: McGraw Hill.

Moreno, L. (2005). Cine y televisión: Las amistades peligrosas [Cinema and television: the dangerous friendships]. Comunicar, 25(XIII), 306-307. Recuperado de http://goo.gl/FoZaF0 el 25 de marzo de 2016.

Ruiz-Olabuénaga, J. I. (2012). Metodología de la investigación cualitativa (Quinta ed.). Bilbao: Deusto.

Sierra, S.-d.-l. (2009). El cine. En T. Cano, Lecciones y materiales para el estudio del derecho administrativo (Vol. VIII-2, pp. 319-346). Madrid: Iustel.

Sierra, S.-d.-l. (2010). Derecho del cine: administración cultural y mercado. Madrid: Iustel.

Sierra, S.-d.-l. (2011a). Cine. En E. Guichot, Derecho de la Comunicación (pp. 233264). Madrid: Iustel.

Sierra, S.-d.-l. (2011b). El Derecho a la diversidad cultural y lingüística y el derecho a una comunicación transparente. En C. Chinchilla, \& M. Azpitarte, Estudios sobre la Ley General de la Comunicación Audiovisual (pp. 157-188). Madrid: Thomson Reuters. Aranzadi. 


\section{MONOGRÁFICO}

Sierra, S.-d.-l. (2012). Cinematografía y audiovisual. En S. Muñoz-Machado, \& M. Rodríguez-Valderas, Derecho de la Regulación Económica. Audiovisual (Vol. V, pp. 531-571). Madrid: Iustel.

Varela, I., García-Santamaría, J. V., Ferrán, T., \& Corberá, J. (2009). El productor ante las políticas de fomento del audiovisual en España y Europa. Actas del II Congreso Internacional sobre Análisis Fílmico (pp. 543-569). Madrid: Complutense. Recuperado de http://goo.gl/CBn92e el 22 de marzo de 2016.

\section{Legislación citada}

UNIÓN EUROPEA. Comunicación de la Comisión sobre la ayuda estatal a las obras cinematográficas y otras producciones del sector audiovisual (texto pertinente a efectos del EEE) C 332/01. DOUE (15 nov., 2013). Recuperado de http://goo. gl/lMtqY0 el 30 de marzo de 2016.

ESPAÑA. Ley 55/2007, de 28 de diciembre, del Cine. BOE núm. 312 (29 dic., 2007). Recuperado de https://goo.gl/d78GzS el 30 de marzo de 2016.

ESPAÑA. Real Decreto-ley, el 6/2015, de 14 de mayo, por el que se modifica la Ley 55/2007, de 28 de diciembre, del Cine. BOE núm. 116 (15 mayo, 2015). Recuperado de https://goo.gl/KPnnJ0 el 30 de marzo de 2016.

ESPAÑA. Real Decreto 1084/2015, de 4 de diciembre, por el que se desarrolla la Ley 55/2007, de 28 de diciembre, del Cine. BOE núm. 291 (5 dic., 2015). Recuperado de https://goo.gl/6UnNMW el 30 de marzo de 2016.

ESPAÑA. Orden ECD/2796/2015, de 18 de diciembre, por las que se establecen las bases reguladoras de las ayudas previstas en el Capítulo III de la Ley 55/2007, de 28 de diciembre, del Cine, y se determina la estructura del Registro Administrativo de Empresas Cinematográficas y Audiovisuales. BOE núm. 306 (23 dic., 2015). Recuperado de https://goo.gl/8BTpUk el 30 de marzo de 2016. ESPAÑA. Orden ECD/2784/2015, de 18 de diciembre por la que se regula el reconocimiento del coste de una película y la inversión del productor. BOE núm. 306 (23 dic., 2015). Recuperado de https://goo.gl/BP2qYe el 30 de marzo de 2016. 